\title{
Knowledge management according to organisational size: A South African perspective
}

\begin{tabular}{|c|c|}
\hline \multicolumn{2}{|c|}{$\begin{array}{l}\text { Authors: } \\
\text { Cornelius (Neels) Kruger }{ }^{1} \\
\text { Roy D. Johnson }{ }^{1}\end{array}$} \\
\hline \multicolumn{2}{|c|}{$\begin{array}{l}\text { Affiliations: } \\
{ }^{1} \text { Department of Informatics, } \\
\text { University of Pretoria, } \\
\text { South Africa }\end{array}$} \\
\hline \multicolumn{2}{|c|}{$\begin{array}{l}\text { Correspondence to: } \\
\text { Neels Kruger }\end{array}$} \\
\hline \multicolumn{2}{|c|}{$\begin{array}{l}\text { Email: } \\
\text { neels.kruger@up.ac.za }\end{array}$} \\
\hline \multicolumn{2}{|c|}{$\begin{array}{l}\text { Postal address: } \\
\text { IT Building, 5th Floor, } \\
\text { Lynnwood Rd, Pretoria 0002, } \\
\text { South Africa }\end{array}$} \\
\hline \multicolumn{2}{|c|}{$\begin{array}{l}\text { Dates: } \\
\text { Received: } 23 \text { Apr. } 2012 \\
\text { Accepted: } 25 \text { Sept. } 2012 \\
\text { Published: } 08 \text { May } 2013\end{array}$} \\
\hline \multicolumn{2}{|c|}{$\begin{array}{l}\text { How to cite this article: } \\
\text { Kruger, C.J. \& Johnson, } \\
\text { R.D., 2013, 'Knowledge } \\
\text { management according } \\
\text { to organisational size: A } \\
\text { South African perspective', } \\
\text { SA Journal of Information } \\
\text { Management 15(1), Art. } \\
\text { \#526, } 11 \text { pages. http:// } \\
\text { dx.doi.org/10.4102/sajim. } \\
\text { v15i1.526 }\end{array}$} \\
\hline \multicolumn{2}{|c|}{$\begin{array}{l}\text { Note: } \\
\text { This article is a continuation } \\
\text { of a study conducted } \\
\text { amongst South African } \\
\text { organisations. An article } \\
\text { within this domain, where } \\
\text { the same data set and } \\
\text { methodology were applied, } \\
\text { was published by the same } \\
\text { authors in Emerald: Aslib } \\
\text { Proceedings } 61(6), 542-562 .\end{array}$} \\
\hline \multicolumn{2}{|c|}{$\begin{array}{l}\text { Copyright: } \\
\text { (C) 2013. The Authors. } \\
\text { Licensee: AOSIS } \\
\text { OpenJournals. This work } \\
\text { is licensed under the } \\
\text { Creative Commons } \\
\text { Attribution License. }\end{array}$} \\
\hline \multicolumn{2}{|l|}{ Read online: } \\
\hline 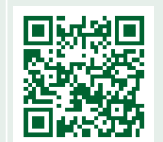 & $\begin{array}{l}\text { Scan this QR } \\
\text { code with your } \\
\text { smart phone or } \\
\text { mobile device } \\
\text { to read online. }\end{array}$ \\
\hline
\end{tabular}

Background: To date, few studies have focused on how embedded Knowledge Managment $(\mathrm{KM})$ is found in the roots of an organisation. Specifically, not much is known whether employees and managers hold similar perceptions regarding KM or if organisational size plays a role in the establishment of KM maturity.

Objective: The objective of this article was to determine what role organisational size plays in the establishment of KM maturity and how different managerial levels viewed their organisations KM maturity.

Method: The authors gained insight into KM maturity in different industry groupings over a five-year period from a large urban South African University engaged in numerous collaboration programmes with industry. In total, 434 employees were interviewed over three grouping levels (operational, middle and senior management).

Results: The findings support arguments that irrespective of organisational size, knowledgeorientated issues are applicable to all organisations. However, with significant differences in scores recorded over all maturity sections in South Africa, the findings indicated that different sized organisations address knowledge-orientated issues differently.

Conclusion: Findings challenge the argument that the manner in which knowledge-orientated issues are addressed differ only slightly depending on organisational size. Smaller-sized organisations prefer a more personal approach, whilst larger-sized organisations prefer knowledge transfer via technology. Irrespective of organisational size, commitment holds the key to $\mathrm{KM}$ success. Commitment shown by middle management regarding $\mathrm{KM}$ is a differentiator.

\section{Introduction}

'Development of meaningful metrics for measuring the value, quality and quantity of knowledge is a key factor for long-term success and growth in KM Systems.' (Alavi \& Leidner 1999)

From the time that Ikojiro Nonaka coined the term 'Knowledge Management' (KM) in a 1991 Harvard Business Review article, practically all organisations have started buying into the KM phenomenon. Many organisations, not realising that KM requires considerable planning and change management, failed in their endeavours dreadfully (Nasir 2003). At the time, studies conducted by Bain and Company (2001) indicated that about 35\% of their world-wide sample of 451 companies were using KM and reported a satisfaction rating of about 3.5 on a 5-point scale. However, reservations regarding KM's value were shared by authors such as Alavi and Leidner (1999), Wilson (2002) and Kazimi, Dasgupta and Natarajan (2004). These authors argued that without substantial proof that KM adds value to organisations, the importance and sufficient commitment needed to embark on KM will be underplayed.

Kruger and Johnson (2011), building on the works of Jennex, Smolnik and Croasdel (2008), argued that discussions in various academic conferences and journals have revealed that there is still no consensus or framework for measuring KM's success. This strongly supports an argument made by Kim (2006) that there was still no standardised framework for measuring KM's success. Alavi (1999); Lee, Lee and Kang (2005); Salojarvi, Furu and Sveiby (2005); Kruger and Johnson (2011) concluded that companies still struggle to develop appropriate metrics to assess the effectiveness of KM initiatives because of limited mechanisms to track the cost and value of KM. According to Zaim, Tatoglu and Zaim (2007), this can be partially explained by the fact that KM was still in its early stages regarding the development of its theoretical base. In cautioning that little empirical work has been undertaken with only a small number of studies focusing on how embedded KM is within organisations, Kruger and Johnson (2011) warn that much work remains to be done both theoretically and empirically before KM can be regarded with the explanatory power that exceeds other frameworks. Beijerse (2000) also argues that for KM to reach any level of acceptance, more comprehensive studies in organisations of different sizes and types are needed. 
Only a small number of studies from the year 2000 have focused on how embedded KM is in organisations and if organisational size plays a significant role in establishing KM maturity. Moffet and McAdam (2006:221) state that there is only, 'a paucity of study that empirically studies the effects of organisational size on the key factors of $\mathrm{KM}^{\prime}$. These authors contest that, 'the majority of studies, in common with other emergent business philosophies, are focused on larger organisations where, for example, readily available implementation resources are an underlying assumption (Moffet \& McAdam 2006:221)'. Zanjani, Mehrasa and Modiri (2009:590) say that 'Despite the profusion of research about KM within large organisations, fewer studies tried to analyze KM in Small and Medium Enterprizes'. Sanghani (2008) states that not much is known regarding $\mathrm{KM}$ in small and medium-sized organisations. According to Sanghani (2008), this is primarily because new management philosophy and technology first being implemented in large organisations, and $\mathrm{KM}$ is no exception in this regard.

Much of the seminal work on KM features large multinational companies. Serenko, Bontis and Hardie (2007:610), in building on earlier works of Bontis $(1999,2001)$, argue that human capital is at the core of any knowledge-based enterprise and come to the conclusion that, 'Much of the extant $\mathrm{KM} / \mathrm{ICT}$ literature is too general when it comes to describe the organisation in which these new efficiencies have a high probability of success'. These same authors caution, 'All organisations are not created equal. One of the biggest glaring differences is their size'. Sanghani (2008) as well as Zanjani, Mehrasa and Modiri (2009) stated that research on the topic of organisational size and KM maturity is insufficient and inundated with conflicting opinions and findings. Zanjani, Mehrasa and Modiri (2009) caution that:

SMEs do not manage knowledge the same way as larger organisations. They normally do not have deep pockets to spend on resources such as land, labor and capital. SMEs must do more with less. (p. 592)

This is in contrast to literature with theory regarding best practice vis-à-vis KM processes and techniques (Garud \& Kumaraswamy 2005) or the relationship between KM and Information and Communication Technologies (ICT) (Alavi \& Leidner 2001; Becerra-Fernandez \& Sabherwal 2001; Earl 2001; Davenport \& Grover 2001; Ryu, Kim, Chaudhury \& Roa 2005). There is only a paucity of research that empirically studies issues such as the following:

- What role does organisation size play in the establishment of KM maturity?

- Do the various managerial levels view their organisation's KM maturity differently?

- Irrespective of organisational size is $\mathrm{KM}$ applicable to all organisations?

\section{Literature review}

'Many questions arise in relation to Knowledge Management and organisational size.' (Moffett \& McAdam 2006:222)

Organisations have to realise that a multitude of factors need to be taken into account before embarking on $\mathrm{KM}$ initiatives
(Alavi \& Leidner 2001; King, Kruger \& Pretorius 2007). Strategy, leadership, culture, information technology, senior management support and structure are all critical factors to KM success (Davenport \& Prusak 1998; Zack 1999; Grant 1991; Hasanali 2002; Snyman \& Kruger, 2004; Xu et al. 2005). Of all these factors, it is leadership commitment (Martiny 1998) and the way we structure organisations that impact on most if not all the human dimensions of the organisation (McMillan 2002). According to Birkinshaw, Nobel and Ridderstrale (2002), the way knowledge is imbedded into a system is the extent to which knowledge is a function of the social and physical system in which it exists. Structure (the relationship between roles in an organisation and its different parts), is thus often seen as an invisible hand that brings organisations to life and gives life to organisations (Mabey, Salaman \& Storey 2001). Davenport and Grover (2001) propose that the focus of $\mathrm{KM}$, as primarily a human dimension, must be structurally based. Birkinshaw, Nobel and Ridderstrale (2002) argue that the strong association between the dimensions of knowledge and organisational structure indicates partial support for the 'fit' hypothesis in contingency theory. This promulgates a shift to all workers and not only those whose primary role is $\mathrm{KM}$.

From the perspective of structural design, and especially in the context of $\mathrm{KM}$, it is often cumbersome to treat the organisation as a unit of analysis. Doing so often disregards knowledge sharing practices within departments, business units or working groups, etcetra. For example, consider the structure of a large, multi-divisional organisation. The multidivisional form of the organisation enables it to engage in completely different markets or products, without the need for much co-ordination (and knowledge sharing) between its divisions. Hence, whilst this might be classified as a large (or even very large) organisation, these are actually separate entities that just happen to have an organisational name in common (Kruger \& Johnson 2010). The same applies to organisations which are really just shareholding collectives. KM investigations in such large organisational structures should be focused at the division or business unit and not at the organisation as a whole. According to Franken and Braganza (2006), the approach to organisational KM can thus not be an unqualified choice but must be closely aligned with the organisational form, structure and size. In debating KM issues, challenges and benefits, Alavi and Leidner (1999) argue that:

there is consistency with the fact that KM systems can be accomplished with different technologies, the most effective of which likely depend upon an organisation's size and existing technical infrastructure. (p. 1)

Although the impact of organisational form, structure and size on group dynamics has been well explored in the social sience literature (Stoel 2002), authors such as Nor and Egbu (2010:234) contest that, 'the impact of size has received less attention in management'. With regards to KM, literature contains an implicit assumption that a standard approach with universal applicability to this process exists, regardless of organisational form, structure or size (Franken \& Braganza 2006). 
Moffett and McAdam (2006) question this proposition and ask if current KM models, frameworks and programmes can be applied across all organisations uniformly. Štrach and Everett (2006) stress that organisational size influences knowledge distribution, whilst Connelly and Kelloway (2003) argue that there is a negative relationship between organisational size and knowledge sharing. There seems to be some debate regarding the impact of organisational size and the successfull institutionilisation of KM (Nor \& Egbu 2010). Unfortunately, with only a small numbers of cases reported, research often provides confusing results:

- As a result of changes in social interactions, there is a negative relationship between organisational size and knowledge sharing (Connelly \& Kelloway 2003).

- As the size of an organisation unit increases, the effectiveness of internal knowledge flow dramatically diminishes whilst the degree of intra-organisational knowledge sharing decreases (Serenko, Bontis \& Hardie 2007)

- The exact KM approach relies heavily on the type and size of the organisation (Davis, Watson \& Man 2007; Zanjani, Mehrasa \& Modiri 2009)

In contrast to this:

- Whilst many knowledge-orientated issues are applicable to all organisations, the manner in which they are addressed differ slightly depending on organisational size (Moffet \& McAdam 2006).

- Organisational size does not have any effect on the initiation and use behavior of KM systems (Xu \& Quaddus 2007).

- Senior general managers most commonly champion KM Systems (Alavi \& Leidner 1999, 2001).

Observations of the South African business environment indicate a growing awareness and adoption of knowledgebased strategies and KM practices (Botha \& Fouche 2002). The authors gained insight into KM in South African industry groupings over a five-year period from a large urban South African University engaged in numerous collaboration programmes with industry. Challenged to amalgamate Western cultures with African cultures, the South African environment portrays a model for businesses in a future full of continued change, diversity and even elements of silent intolerance and conflict (Finestone \& Snyman 2005). Deeprooted political and social requirements to integrate different cultures, not in a manner where one culture dominates whilst others become extinct over time (Prime 1999), make the South African environment unique in many aspects (King, Kruger \& Pretorius 2007).

South Africa has been challenged to make the transition into the global economy whilst managing the vast diversity of its people (Prime 1999). South Africa has past political history that this article will not discuss in detail, except for a few factors believed to directly effect KM maturity. One of these factors is the policy of affirmative action. Affirmative action has the potential of empowering one group over the sanctioning of another which influences job security and consequently leads to an unwillingness of people to share knowledge (Finestone \& Snyman 2005).

Another barrier to KM in the South African context is the issue of language. People are reluctant to share knowledge if they cannot understand concepts or find it difficult to convey their message. Language problems in South Africa are heightened by nine ethnicities, each with its own communities, cultural languages and parlance (Prime 1999). Communication, which is a major element of knowledge-sharing and the vesting of KM maturity, is often severely hampered when having to deal with 11 official languages. Different communication styles are more prevalent in different cultures. White South Africans predominantly adhere to Western culture preferring an explicit style of communication such as written commitments (i.e. contracts) as the main indication of trust. In contrast, Black African cultures are more implicit in their manner of communication and prefer oral communication (King, Kruger \& Pretorius 2007).

Strongly linked to communication, is the way South African organisations are managed. According to Prime (1999), in other multi-cultural countries, one culture typically dominates whilst others coexist. South Africa is differentiated by the influx of different cultural pressures that need to be integrated if businesses want to compete in the global economy. South Africa is unique because of its social, political and economic history. In contrast to other culturally diverse countries, South Africa aims to create a unified culture wherein European, African and Asian cultures are fused (Finestone \& Snyman 2005).

Whilst the theoretical relevance of studying the link between organisational size and management might be well debated in literature, finding practical examples remains problematic. The intent of this article is to move past theoretical propositions and investigate $\mathrm{KM}$ maturity in different organisational groupings and sizes ${ }^{1}$. The contribution of this paper is to address the research questions that follow:

- What role does organisation size play in the establishment of KM maturity?

- How do the various managerial levels view their organisation's KM maturity?

\section{Methodology and data collection}

In this extremely diversified South African setting, the authors applied the questionnaire developed by Kruger and Snyman (2007) to a set of 86 organisations. The questionnaire appealed to the researchers primarily because it is built upon the proposition that for KM to be of value, it must progress (mature) to the point where knowledge is seen as a strategic resource with Information and Communication Technologies (ICT) and Information Management (IM) as enablers to KM. In this context, Kruger and Snyman (2007) support the argument made by Grey (1998) and define the difference between

1.Organisations selected represented a cadre of organisations servicing fairly homogenous markets/products. All organisations selected structures adhere to
modern management theory that is organisational structures are mostly centralised, functionally specialised and hierarchical in nature. 
knowledge and IM. The difference is that IM is concerned about working with objects (i.e. data or information) whereas $\mathrm{KM}$ is concerned about working with people. Emphasis was not placed on achieving total representation in determining a 'usable population' (population size that is applicable to both Secondary Data Analysis (performance assessment) and evaluative (KM Maturity assessment and performance assessment research), but rather on purposefully selecting a usable and obtainable population size for comparative purposes. Guided by the classification index supplied by the Johannesburg Stock Exchange (JSE) handbook of July-December 2005 (Profile's Stock Exchange Handbook 2005), organisations of similar size and similar operations were purposely selected and grouped together for the research to be undertaken. Considering that it would be difficult for personal knowledge sharing to flourish given issues such as language differences, time zones, geographical dispersion and cultural differences within the organisation, care was taken not to include large, global organisations or diversified organisations that engage in a number of different markets or products.

Preliminary research attempts showed an unwillingness of organisations to participate in the intended research because of organisational sensitivity and confidentiality plus availability of information. This problem was overcome by incorporating a research component into the curriculum of Master in Business Administration (MBA), Master in Information Technology (MIT) and Master in Commerce (MCom) students of a large urban university in South Africa. Because most of these students were active practitioners $(97 \%)$ and considered 'senior' with regard to academic achievement as well as work experience, they became suitable surrogates to participate in the research project. (This research study involving human subjects was approved by an Ethics Committee of the same university).

After numerous lectures and discussions dealing with data, information, knowledge and KM, senior practitioners used the KM Maturity Assessment Questionnaire (KMMAQ) by Kruger and Snyman (2007) to critically evaluate the KM Maturity of their own organisation or one with which they were deeply familiar. To minimise bias caused by self reporting, subjects were instructed on the need for objectivity through group and one-on-one discussions as well as through individual debriefing when questions arose. Only volunteering practitioners (and organisations) were allowed to participate in the study. In total 178 senior practitioners from nine industry groupings participated in the research conducting three structured interviews per practitioner. In order to sample each of the managerial levels, practitioners were instructed to conduct structured interviews amongst operational personnel, middle management as well as strategic personnel in their respective organisations.

The study sample consisted of 434 employees from 86 South African based organisations. Considering the diversity of organisations participating in the study, the sample population included individuals from diverse backgrounds and cultures. The sample chosen was thus representative of the managerial levels present in organisations (operational personnel totalled 143, middle management 158 and senior management 133). Data collected by means of the structured KMMAQ was digitalised through keyboard entry and transferred to a rating system. In order to ensure a clean and error-free data set, the process of data capturing was closely monitored to ensure as few errors as possible. Newly imported data was checked for capturing errors via standard validation checks as applied by the university. Checks included frequencies, maximum, minimum, range and checks for missing values. All statistical calculations were verified by the Bureau for Statistical and Survey Methodology (Statomet). Statomet is a facility that focuses on the scientific design and management of research. Statomet provides statistical advice on all aspects of research design and management, and aims to improve the quality of research by rendering a multi-disciplinary service to public and private organisations.

After the verification process had been completed, all data collected was carefully prepared for tabular and graphic presentation, analysis and interpretation. The computer software used for analysis and modelling was SAS version 8.3 from the SAS Institute ${ }^{\mathrm{TM}}$. All graphs and figures were created using Microsoft Excel (2007). The analysis that follows consists of the descriptive statistics used for each question. Descriptive statistics involved arranging, summarising and presenting the data in such a way that the meaningful essentials of the data could be extracted and easily interpreted. Statistics used established the basic statistical measures of the response variable for every question covering aspects pertaining to ICT and IM. Unless specifically stated, in all instances, findings were elaborated upon from a positive affirmation 'yes, definitely' and 'yes, but not significantly'. Where the probability of exceeding the norm ( $p$-value) was found to be less than 0.05 , the decision rule was to reject the null hypothesis at a 5\% level of significance. (Full details of all statistical analysis done, as well as a summary of all results obtained, are available on request from the authors).

\section{Discussion, results and findings}

Although the questionnaire by Kruger and Snyman (2007) addresses the total spectrum of KM maturity, this article only focuses on the role organisation size plays in the establishment of KM maturity and how the different managerial levels view their organisations KM maturity. We will explore this in the section below.

\section{Knowledge management maturity by organisational size}

In order to determine if organisational size plays a role in $\mathrm{KM}$, it was decided to group participating organisations into four categories. Organisations with 100 and less employees were grouped into the 'small organisation' category. Organisations with between 101 and 2000 employees were grouped into 'medium-sized organisations', 2001-2005 employees into 'large organisations' and organisations of above 25000 grouped into 'extra-large organisations'. The selection of 
organisational sizes led to a fairly even distribution of the total research population (Table 1).

Organisations selected represented a cadre of organisations servicing fairly homogenous markets or products. All organisations-selected structures adhere to modern management theory (i.e. organisational structures are mostly centralised, functionally specialised and hierarchical in nature).

Through a process of inductive reasoning, Kruger and Snyman (2007) have argued that certain issues, policies and strategies are crucial to effective and efficient KM. The main thrust of the argument was the proposition that when $\mathrm{KM}$ issues are institutionalised in chronological order, the institutionalising entity (i.e. organisation) becomes more strategically evolved. In essence, it was proposed that the process of institutionalisation of KM from within a managerial or strategic, rather than from within a technological perspective, aids in the transference of tacit knowledge into explicit knowledge, progressively enabling the exponential exploitation of the power of knowledge.

Kruger and Snyman (2007) propose that before any endeavour in $\mathrm{KM}$ commences, as a preliminary phase, a certain amount of ICT and information management (as enablers of effective KM) must be present in the organisation. The next phase, requires a realisation of the importance of $\mathrm{KM}$ as a formal function within the organisation, as well as associated drives to instil this realisation throughout the organisation. This phase in KM maturity is followed by conscious commitment, especially from business managers, to start embracing endeavours in KM. At this level of maturity, ICT and (IM) must already be geared towards supporting KM endeavours.

Phase 4 centres around the ability to consciously formulate a strategy (knowledge strategy) about knowledge as a strategic resource. Typically at this stage of maturity, ICT should by now also be geared to support the assimilation and distribution of knowledge in all spheres of the organisation. The next level of maturity deals with the ability to both exploit and explore the power vested in knowledge and KM (formulate KM strategies). The essence of this level of maturity is thus not only the ability to enhance strategy formulation intentionally, but also to streamline KM processes and procedures.

As soon as organisations are capable of enhancing strategy via $\mathrm{KM}$, the final evolutionary step is the incorporation and utilisation of knowledge vested in the organisation's value chain and value chain partners. The primary requirement of this level of maturity is the ability to transcend the borders of the organisation. This is the ability not only to share data and information, but also knowledge and expertise with all stakeholders in the organisation's value chain.

In using the KMMAQ proposed by Kruger and Snyman (2007), an overall KM maturity score could be calculated for all participating organisations. The total score achieved was calculated by adding the scores in each maturity section together. These sections included 20 points for ICT as an Enabler of KM, 76 points for IM as an Enabler of KM, 88 points for the successful identification of KM Issues, Policies and Strategies, 94 points for Implementation of KM, 76 points for Ubiquitous Knowledge (extending KM beyond the borders of the organisation) and four points for Growth in KM (over the past five years). Different maturity sections contributed different weights to the overall maturity score achieved. The total score achieved per organisation, organisational grouping or organisational size was thus calculated by dividing the total score achieved by the total score achievable (358). The average KM maturity score obtained by all 86 participating organisations totalled 175.36 points, or $48.98 \%$. With regard to growth in KM maturity, slightly more than twenty percent $(20.28 \%)$ of interviewees indicated that their organisations experienced rapid growth in KM maturity over the past five years (2003-2007), 52.12\% are of the opinion that although growth occurred it was not significant and $22.17 \%$ state that although no growth took place there will probably be growth within the next five years. Slightly more than five percent $(5.43 \%)$ were of the opinion that a decline in KM growth occurred over the past five years (Table 2). Full details of all statistical analysis done as well as a summary of all results obtained are available from the authors on request.

In grouping organisations according to size, small organisations achieved an average KM maturity of $43.51 \%$ (155.76/358), whilst organisations with between 101 and 2000 employees (medium-sized organisations) averaged $50.03 \%$. Large organisations (2001-25 000 employees) scored a bit lower than medium-sized organisations with a $48.87 \%$ average. Organisations with more than 25000 employees (extra-large organisations) consistently outperformed all other organisations, scoring on average 53.75\% (Table 3).

TABLE 1: Organisations per category.

\begin{tabular}{ll}
\hline Category & $\%$ \\
\hline Small (1-100) & 21 \\
Medium (101-2000) & 24 \\
Large (2001-25 000) & 21 \\
Extra-large (25001+) & 19 \\
\hline
\end{tabular}

TABLE 2: Knowledge management maturity distribution of all questionnaires.

\begin{tabular}{|c|c|c|c|c|c|}
\hline Variable & $N$ & $\begin{array}{l}\text { Mean } \\
(\%)\end{array}$ & Minimum & Maximum & Possible \\
\hline $\begin{array}{l}\text { Section } 1 \\
\text { ICT Management }\end{array}$ & 433 & 73.60 & 2 & 20 & 20 \\
\hline $\begin{array}{l}\text { Section } 2 \\
\text { Information } \\
\text { Management }\end{array}$ & 434 & 61.14 & 8 & 76 & 76 \\
\hline $\begin{array}{l}\text { Section } 3 \\
\text { KM Issues Policies and } \\
\text { strategy }\end{array}$ & 434 & 51.75 & 0 & 88 & 88 \\
\hline $\begin{array}{l}\text { Section } 4 \\
\text { Implementation of KM }\end{array}$ & 433 & 46.50 & 9 & 90 & 94 \\
\hline $\begin{array}{l}\text { Section } 5 \\
\text { Ubiquitous knowledge }\end{array}$ & 434 & 30.27 & 0 & 76 & 76 \\
\hline $\begin{array}{l}\text { Section } 6 \\
\text { KM growth over past } \\
\text { five years }\end{array}$ & 424 & 51.88 & 0 & 4 & 4 \\
\hline Total & 434 & - & 47 & 311 & 358 \\
\hline
\end{tabular}

$N$, number; ICT; information and communication technologies; KM, knowledge management. 
This average could result from the resources available to extra-large organisations as discussed later.

An analysis of variance (ANOVA) with $p$-values $<.0001$, indicated that there is a significant difference between the mean scores achieved in different organisations based on size. Multiple comparisons (Least Squares Means) identified that the biggest differences occurred between small and all other organisational sizes. Medium-sized organisations achieved similar scores $(<=5 \%)$ to large and extra-large organisations, except for maturity Section 1 (ICT) and Section 5 (Ubiquitous Knowledge) where the mean scores of medium-sized organisations were significantly lower $(>5$, than the scores of extra-large organisations. Scores of large organisations were similar $(<=5 \%)$ to other organisations' scores, except for Sections 1 (ICT) and 5 (Ubiquitous knowledge), where it was higher (> 5\%), than small organisations' scores. Over all maturity sections, extra-large organisations scores' were higher $(>5 \%)$ than the scores achieved by small organisations. There was also a difference of more than $5 \%$ in scores achieved by extra-large organisations, compared to large organisations in Section 2 (IM) and between extra-large and medium-sized organisations in Section 5 (Ubiquitous knowledge). In essence small and extra-large organisations yielded different scores, with medium and large organisations forwarding similar scores.

Findings indicated that extra-large organisations are at an advantage when it comes to the institutionalisation of formal KM practice over all maturity sections. However, of interest is that although large organisations outperformed smaller organisations (small and medium-sized organisations) in Sections 1 (ICT) and 5 (Ubiquitous Knowledge) of the questionnaire, they were outperformed by mediumsized organisations when it comes to IM (Section 2) the formulation of KM Issues, Policy and Strategy (Section 3) and the institutionalisation of KM practice (Section 4).

As a rule, extra-large organisations do have access to considerably more resources than smaller sized organisations, possibly explaining why extra-large organisations (25 000+ employees) obtained higher scores for all maturity levels than all other organisational sizes. Extra-large organisations are also more likely to be mature with regard to implementing policies and strategies because of legal and mandatory requirements (Moffet \& McAdam 2006). The lower scores achieved by large organisations compared to the scores achieved by medium-sized organisations (especially in maturity Section 2, Section 3 and Section 4) suggest that there could be a 'break-even point' between resources available and the successful institutionalisation of KM because of organisational size. This argument necessitated taking into account not only organisational size, but also the different managerial levels present within organisations. Specifically, analysis needed to include a study of the diffusion (point difference between managerial levels) of KM by organisational size and setting.

\section{Knowledge management maturity as a function of managerial levels}

In studying $\mathrm{KM}$ in such a multi-cultural environment as South Africa, King, Kruger and Pretorius (2007) found that most respondents who have three or fewer years of experience at an organisation are more likely to feel that the organisation has a corporate culture that encourages knowledge sharing. However, this feeling decreases with individuals who have four and seven years' experience in the organisation. According to King, Kruger and Pretorius (2007), the reason this value decreases could be the result of inexperience and/or competition for promotion. These authors argue that this contention is supported by the fact that individuals who have eight or more years of experience feel more secure in their jobs, agreeing to a greater extent that organisational culture is supportive of KM. King, Kruger and Pretorius (2007) proposed that experience is the biggest factor related to the frequency of respondents feeling they could benefit from a KM system. Specifically, they found that senior managers are the most likely to agree that the organisation would benefit from KM.

Figure 4 supports the findings of King, Kruger and Pretorius (2007) showing that senior managers scored their organisation's maturity at $53.48 \%$; middle managers at $47.89 \%$ and operational personnel at $46.00 \%$. This constitutes an overall difference in scores between senior management and operational personnel of $7.5 \%$. Of interest is the difference between the scores where senior managers and middle managers $(5.59 \%)$ is significantly higher than the difference in scores reported by middle managers and operational personnel $(1.89 \%)$. Senior managers consistently rated the maturity of the different sections higher than middle and operational personnel. There is about a 10\% discrepancy between the scores allocated by senior and middle managers to Section 3 of the questionnaire which deals with the formulation of KM issues, policies and strategies (Table 4)

Analysis of variances (ANOVA), with a $p$-value $<.0001$ indicated that there is indeed a statistical difference between the score recorded by the different managerial levels over maturity Section 1 to Section 4. However, scores reported for maturity Section 5 and Section 6 were found not to differ significantly $(0.07 \%)$ between the scores recorded by the different managerial levels. In order to determine where differences occurred, it was established that within Section 2 (IM), Section 3 (KM Issues, Policy and Strategy) and Section 4 (Implementation of $\mathrm{KM}$ ) differences were found primarily between the values by operational and senior managers and middle and senior managers (The GLM procedure of Least Squares Means was used to determine where difference occurred). The values by operational personnel and middle managers were found not to be significantly different. These findings not only support the argument by King, Kruger and Pretorius (2007) that senior managers are more likely to agree that the organisation would benefit from KM, but also indicates at an over-estimation by some senior managers regarding, (1) the success of implementation 
TABLE 3: Knowledge management maturity distribution organisational size.

\begin{tabular}{|c|c|c|c|c|c|c|c|}
\hline \multirow[t]{2}{*}{ Organisational size } & \multicolumn{6}{|c|}{ Section } & \multirow[t]{2}{*}{ Total } \\
\hline & 1 & 2 & 3 & 4 & 5 & 6 & \\
\hline Small & 65.38 & 55.59 & 46.81 & 42.87 & 22.66 & 43.68 & 43.51 \\
\hline Medium & 73.91 & 62.78 & 53.47 & 47.8 & 29.53 & 55.24 & 50.03 \\
\hline Large & 76.01 & 59.75 & 50.38 & 45.5 & 33.39 & 51.78 & 48.87 \\
\hline Extra-large & 79.1 & 66.71 & 56.58 & 50.04 & 36.29 & 56.25 & 53.75 \\
\hline
\end{tabular}

TABLE 4: Knowledge management maturity as a function of different managerial levels.

\begin{tabular}{|c|c|c|}
\hline \multirow[t]{2}{*}{ Managerial level } & \multirow[b]{2}{*}{1} & \multirow[b]{2}{*}{2} \\
\hline & & \\
\hline Ops & 69.79 & 57.8 \\
\hline Middle & 72.15 & 60.32 \\
\hline Senior & 79.46 & 65.72 \\
\hline \multicolumn{3}{|c|}{$\begin{array}{l}\text { of IM, (2) the efficiency and effectiveness of } \mathrm{K} \\
\text { policies and strategies and (3) sufficient support gi } \\
\text { institutionalisation of KM endeavours. }\end{array}$} \\
\hline
\end{tabular}

When differences in opinion with regard to $\mathrm{KM}$ maturity reported by the different managerial levels are viewed from the perspective of different organisational sizes, the picture changes dramatically (Table 5). As a point of departure, an Analysis of Variances (Two-way ANOVA) was done to determine if there is indeed a difference between the score achieved per organisational size and the scores recorded per managerial level. Again it was confirmed that the mean values recorded by the different managerial levels and organisational size are statistically different.

In comparing the totals by operational, middle and senior personnel to one another with a GLM Procedure (Least Square Means), it was confirmed that the scores of operational personnel and middle managers are similar in small, medium and large organisations. However, scores of operational personnel and middle managers in extra-large organisations were different. Also, within extra-large organisations, the scores of senior managers were found to be similar to the scores recorded by middle management.

Excluding small organisations, senior managers scored KM maturity fairly evenly over all maturity sections (Table 5). In contrast, middle managers within extra-large organisations scored maturity considerably higher than middle managers in other organisations. Of interest is that the decline in scores between senior and middle managers is the smallest within extra-large organisations and the largest within large organisations. In contrast, the difference in score between middle and operational personnel is the smallest within large and medium-sized organisations and the largest in extralarge organisations. These findings support Connelly and Kelloway (2003), plus Serenko, Bontis and Hardie (2007), that the size of the organisation does play a role in the diffusion of $\mathrm{KM}$ between the different managerial levels.

Within small organisations, operational personnel rated KM management maturity at $41.94 \%$, middle management scored maturity basically the same at $42.27 \%$, whilst senior managers forwarded a maturity score of $47.10 \%$. The difference in score between top management and operational personnel $(5.2 \%)$ is the lowest of all organisational sizes analysed. Of interest is that within small organisations there is a fairly even distribution between the overall scores attributed to senior, middle and operational personnel with regard to maturity in Section 2 (IM), Section 4 (Implementation of KM), Section 5 (Ubiquitous knowledge) and Section 6 (Growth in KM). However, in Section 3 (the identification and institutionalisation of KM Issues, Policies and Strategies), senior managers consistently recorded scores higher than those by interviewees from middle and operational personnel. This again hints at middle and operational personnel within small organisations viewing the formulation of KM issues, policies and strategies to be less successful than senior managers do.

In contrast to small organisations, scores attributed to senior managers in medium-sized organisations were consistently higher $(54.83 \%)$ over all maturity sections than the scores recorded by middle and operational personnel totalling $48.34 \%$ and $47.55 \%$ respectively. Scores recorded by middle and operational personnel are nearly identical over all sections. Over all maturity sections there is a difference of about $7 \%$ between the scores recorded by senior managers, and middle and operational personnel. This strongly hints at a difference in perception regarding senior middle and operational opinions of KM maturity. Although senior managers in medium-sized organisations are starting to acknowledge the value of $\mathrm{KM}$, it has possibly not evolved beyond the strategic level.

This quandary is supported by a senior manager in a medium-sized service delivery company stating that:

'We have experienced quite strong growth in terms of KM maturity over the last five years. This is indicated by the establishment of a number of initiatives including Organisational Education and Training and the establishment of a Research and Development department, a definite step towards active KM'. (Senior manager, delivery company)

This manager continues that, 'Despite the fact that the R\&D department provides management and other verticals valuable information, they have yet to become actively 
TABLE 5: Knowledge management maturity ratings as a function of different managerial levels within different organisational sizes.

\begin{tabular}{lccccc}
\hline Managerial level & \multicolumn{5}{c}{ Size } \\
\cline { 2 - 6 } & Small & Medium & Large & Extra-large & Average \\
\hline Ops & 41.94 & 47.55 & 45.18 & 49.45 & 46 \\
Middle & 42.27 & 48.34 & 46.08 & 55.62 & 47.89 \\
Senior & 47.1 & 54.83 & 55.67 & 56.26 & 53.48 \\
\hline
\end{tabular}

involved in the formulation of strategies'. A senior manager at a South African water utility organisation shares a similar sentiment and argues that:

'Our organisation has realised the importance of KM as a strategic resource and has decided on KM principles. What is still outstanding is the formulation of organisational-wide knowledge policy that will enable the organisation to implement KM initiatives'. (Senior manager, South African water utility organisation)

A possible explanation for differences in scores could be that although there are clear-cut strategic initiatives driven by top managers, such strategy is not becoming policy resulting in managers and operational personnel not buying in and not becoming sensitive to KM initiatives.

In large companies, scores attributed to senior managers were considerably higher $(55.67 \%)$ than the scores attributed to middle $(46.08 \%)$ and operational personnel $(45.18 \%)$ as seen in Table 5 . Scores recorded by middle and operational personnel were again nearly identical over all maturity sections. The disparity of about $10 \%$ between the scores attributed to senior and middle management is mostly attributed to differences in scores in Section 2 (IM), Section 3 (Formulation of KM Issues, Policy and Strategy) and Section 4 (Implementation of $\mathrm{KM}$ ) of the questionnaire. Comments made by middle managers working in a large pharmaceutical company manufacturing facility support the argument that senior management is overestimating KM maturity or supplying lip service to KM in stating that, 'the company does not have a clearly defined KM strategy and policy in place and staff members (especially management) are not evaluated on their ability to share knowledge'. This manager not only argues that perceptions surrounding KM differ greatly, but that there is also a 'perception that the ICT department is $\mathrm{KM}$ and not the enabler of $\mathrm{KM}^{\prime}$. He also expresses a strong opinion that, 'there is not a significant drive to get all employees involved in $\mathrm{KM}$ and expertise is held locally within functional departments, like IT, finance, production, etcetra.' This position was supported by the following quote from a senior manager working for a large financial institution:

'At the moment some members of the board are of the opinion that $\mathrm{KM}$ is part of IT management and should thus be incorporated into the IT department. This is creating confusion on who does what'. (Senior manager, employee, financial institution)

A senior manager at a large ICT company made a similar statement that:

'Our organisation has not yet reached a level whereby KM is able to seamlessly integrate with the eco-system of the enterprise. $\mathrm{KM}$ is still a separate entity although there is a great awareness, but its effectiveness is still yet to be realised'. (Senior manager, employee, ICT company)
At another large pharmaceutical company, managers indicated that various initiatives have been explored to effectively handle data and information. These managers are in agreement that there is an understanding of the importance of managing, securing and protecting knowledge as a strategic resource. However, according to one of the managers interviewed, 'Although our company realises the importance of $\mathrm{KM}$ policies and strategies, our implementations of KM as well as our level of ubiquitous knowledge are at lower maturity levels'.

Apart from Section 5, in extra-large organisations, scores attributed to senior (56.26\%) and middle managers (55.62\%) are significantly higher and smaller in difference than the scores recorded by operational personnel (49.45\%). In some instances, scores recorded by middle managers were even slightly higher than the scores recorded by senior managers (Section 2 (IM) and Section 4 [implementation of KM]). This hints at differences in perception regarding the formulation of KM issues, policy and strategy, possibly being more the result of insufficient communication or the time delay associated with the diffusion of policy beyond the strategic domain, than unwillingness by management to implement KM. This argument is supported by a comment made by one of the executives interviewed in an extra-large organisation saying:

'The organisation has realised the importance of KM as a strategic resource and has decided on KM. What is still outstanding is the formulation of an organisational-wide knowledge policy that will enable the organisation to implement KM initiatives'. (Executive, extra-large organisation)

In the words of a senior manager from a major automotive parts manufacturer, 'Leadership and organisational culture are the two distinguishing inhibitors of levering existing knowledge to enhance performance and gain competitive advantage'. This manager also supplied an explanation for differences in scores by different managerial levels and argued that, 'While pockets of the company are advanced in knowledge creation and management, initiatives are not corporate-wide and therefore not sustainable'.

\section{Conclusion}

The South African scenario can be considered a benchmark for developing economies characterised by continued change, diversity and even elements of silent intolerance and conflict. The research results meet the demand for quantative research in providing an understanding within the particular South African context. In this article it is argued that the debate surrounding ICT, IM and KM is drawing attention away from the determining factor in KM's survival (i.e. acceptance and use). Current literature is largely neglecting this phenomenon. To date, not many studies are focusing on the amount of KM growth that is occurring in ordinary organisations, if organisation size plays a role in the establishment of KM maturity or if employees and managers hold similar opinion regarding KM.

In contrast, KM might be a fallacy not able to withstand the test of time as Wilson (2002) would contest with only 
$33.60 \%$ of South African organisations indicating that no growth or a decline in KM growth occurred over the period 2003-2006. South African industry can be considered a data point for Western industry with an environment characterised by continued change, diversity and even elements of silent intolerance and conflict. This finding is of extreme importance to KM practitioners, scholars and professionals. In moving past theoretical propositions and investigating $\mathrm{KM}$ as it relates to different organisational settings and managerial levels, it can be concluded that $\mathrm{KM}$ is taking on a new dimension. A dimension where $\mathrm{KM}$ is growing in stature and becoming a self-governing entity dependent upon, but separate from, ICT and IM.

To answer the question, 'What role does organisational size play in the establishment of KM maturity?', analysis of KM maturity revealed that there are significant statistical differences between small, medium, large and extra-large organisations. Findings support Moffet and McAdam's (2006) argument that irrespective of organisational size, knowledgeorientated issues are applicable to all organisations. This emphasises Moffet and McAdam's (2006) and Xu, Quaddus, Sankaran and Faranda's (2005) reservation that the manner in which knowledge-orientated issues are addressed differ only slightly depending on organisational size. The findings support that the concept of $\mathrm{KM}$ is applicable to all organisations and that there is basically no significant difference in KM between organisations of different sizes. These finding thus strongly support the arguments proposed by $\mathrm{Xu}$ et al. (2005). Of interest is that although KM elements are applicable to all organisations, it is the approach to implementation that seems to vary, as Moffet and McAdam (2006) rightfully contest. With significant differences in scores recorded over all maturity sections, findings strongly hint that different-sized organisations address knowledgeorientated issues differently. In support of findings by Moffet and McAdam (2006); Sadler-Smith, Sergeant and Dawson (1998); Corso, Martini, Paolucci and Pellegrini (2003), Xu, Quaddus, Sankaran and Faranda (2005), as well as Zanjani, Mehrasa \& Modiri (2009), smaller-sized organisations prefer a more personal approach, whilst bigger-sized organisations prefer knowledge transfer via technology.

Findings revealed that although large organisations (NOT extra-large organisations) outperformed medium-sized organisations in Section 1 (ICT Management) and Section 5 (Ubiquitous Knowledge) of the questionnaire, they were often outperformed by medium-sized organisations with regard to the Management of Information (Section 2), the vesting of KM Issues, Policy and Strategy (Section 3) and the Institutionalisation of formal KM Endeavours (Section 4). As far as medium to large-sized companies are concerned, findings are thus supportive of Connelly and Kelloway's (2003) and Serenko, Bontis and Hardie's (2007) arguments that there could be a 'break-even point' between resources available (technology in support), the size of the organisation and the ability to share knowledge. However, in contrast to Connelly and Kelloway's (2003) and Serenko, Bontis and Hardie's (2007) findings that there is often a negative relationship between organisational size and knowledge sharing, extra-large organisations recorded the highest scores over most maturity levels. Of interest was that high scores were not only the result of consistency in achievement over all maturity levels, but also the result of higher than average scores recorded by middle management. This strongly indicates that diffusion of $\mathrm{KM}$ has a much larger impact on KM maturity than often anticipated. Hence, larger organisations are turning to collaborative systems where information flow is aided by personal contact, as proposed by McGovern and Norton (2002).

In answering the question, 'How do different managerial levels view their organisations KM maturity?', scores differ primarily between operational personnel and managers with regard to maturity in IM (Section 2), the identification of KM Issues, Policy and Strategy (Section 3) and the Implementation of KM (Section 4). An interesting observation is that there is about a $10 \%$ discrepancy between the scores allocated by senior and middle managers in Section 3 of the questionnaire, which deals with the formulation of KM Issues, Policy and Strategy. Middle and operational personnel do not share the same sentiment regarding the success of KM, as do senior management. Although this finding is not directly related to the argument proposed by King, Kruger and Pretorius (2007), the finding supports the notion that individuals with more than eight years experience are more likely to view organisational culture as supportive of KM. Excluding small organisations, senior managers scored KM maturity fairly evenly over all maturity sections. In contrast, middle managers within extra-large organisations scored KM maturity considerably higher than middle managers in other organisations. Of interest is that the decline in score between senior and middle managers is the smallest within extra-large organisations and the largest within large organisations. In contrast, the difference in score between middle and operational personnel is the smallest within large and medium-sized organisations and the largest in extra-large organisations.

Findings confirm that there is a symbiotic relationship between diffusion of KM between managerial levels and organisational size and that the two should not be studied in isolation. These findings thus support Connelly and Kelloway (2003) as well as Serenko, Bontis and Hardie (2007) that the size of the organisation does play a role in the diffusion of KM between the different managerial levels. However, there findings add a new dimension to the argument that there is a negative relationship between organisational size and knowledge sharing. As the size of an organisation unit increases, the effectiveness of internal knowledge flows dramatically diminishes, whilst the degree of intraorganisational knowledge sharing decreases. Findings hint that depending on the size of the organisation, the spread in diffusion between different managerial levels changes from large differences between all the lower levels of management (operational personnel and middle management) and senior management, to large differences between all managers (middle and senior management) and operational levels. 
It becomes clear that although organisational size and the availability of resources are influencing the successful institutionalisation of $\mathrm{KM}$, the establishment of sound $\mathrm{KM}$ practice and the sharing of knowledge might be more dependent on a deliberate, conscious and calculated managerial effort and support by top management ( $\mathrm{Xu}$ et al. 2005). Irrespective of organisational size, commitment holds the key to KM success. This is in support of Connelly and Kelloway (2003) that management support for KM is a significant predictor of its success. Commitment by middle management will be a differentiator.

\section{Limitations and applicability of the study}

A limitation of the study was that it was based solely on South African industry. A second constraint is the level of aggregation, which could be overcome by closer examination of the component organisations. Replicating this study in other developing as well as developed countries would be most informative. In the same light, a longitudinal study might identify trends in different industries, regions and capital markets. The questionnaire used is intended to assess a company operating on free market principles and might be ineffective for use in assessing companies operating in an oligopolistic market.

The use of a 4-point Likert scale, used in the KM Maturity Questionnaire may not be sensitive enough. Expanding the number of possible responses might offer a more nuanced analysis of trends. Considering that the subjects of research have been drawn in as integral parts of the research design, manipulation caused by 'overly emotional or subjective involvement' could have occurred because of respondents serving their own, rather than the research needs. Another quandary to be further investigated is why middle management respondents in extra-large organisations are consistently closer to the scores reported by senior management than by operational personnel.

Whilst varying conceptions of KM exist amongst Eastern and Western theorists, this study provides valuable baseline data which can support further studies of both local and global significance. Such investigations can explore varying perceptions of technology, information and knowledge outside the scope of this study. However, this study does set the stage for investigating diversity in conceptions and implications for perceptions of management modes. The baseline data presented can thus inform other empirical studies that investigate differences regarding knowledge sharing in different sized organisations. Further studies can also probe the significance of cultural differences precipitated by race, age, ethnicity, gender, et cetera, in both further defining agreement on the meaning of these terms and also exploring the implications of such insights for usage and adoption of $\mathrm{KM}$ in all spheres of organisational diversification, including leveraging its potential for organisational innovation and advancement.

\section{Acknowledgements Competing interests}

The authors declare that they have no financial or personal relationship(s) which may have inappropriately influenced them in writing this paper.

\section{Authors' contributions}

C.J.K. (University of Pretoria) was the project leader, responsible for the experimental and project design and for the drafting of the manuscript. R.D.J. (University of Pretoria) prepared the calculation and the tables, and revised and edited the manuscript.

\section{References}

Alavi, M. \& Leidner, D.E., 1999, 'Knowledge management systems: Issues, challenges, and benefits', Communications of the Association for Information Systems, Vol. 1 , Article 7.

Alavi, M. \& Leidner, D.E., 2001, 'Review: Knowledge management and knowledge management systems: Conceptual foundations and research issues', MIS Quarterly 25(1), 107-136. http://dx.doi.org/10.2307/3250961

Becerra-Fernandez, I. \& Sabherwal, R., 2001, 'Organisational knowledge management: A contingency perspective', Journal of Management Information Systems 18(1), 23-55.

Beijerse, R.P., 2000, 'Knowledge management in small and medium-Sized companies: Knowledge management for entrepreneurs', Journal of Knowledge Management 3(2), 94-110. http://dx.doi.org/10.1108/13673279910275512

Birkinshaw, J., Nobel, R. \& Ridderstrale J., 2002, 'Knowledge as a contingency variable: Do the characteristics of knowledge predict organisational structure?', Organisational Science 13(3), 274-289. http://dx.doi.org/10.1287/ orsc.13.3.274.2778

Bontis, N., (1999), 'Managing organisational knowledge by diagnosing intellectual capital: Framing and advancing the state of the field'. International Journal of Technology Management 18(5), 433-485. http://dx.doi.org/10.1504/ of Technology
IJTM.1999.002780

Bontis, N., 2001, 'Assessing knowledge assets: A review of the models used to measure intellectual capital', International Journal of Management Reviews 3(1), 41-60. http://dx.doi.org/10.1111/1468-2370.00053

Botha, D.F. \& Fouché, B., 2002, 'Knowledge management practice in the South African business sector: Preliminary findings of a longitudinal study', South African Journal of Business Management 33(2), 13-19.

Bain and Company, 2001, Management tools, Boston, MA.

Connelly, C.E. \& Kelloway, K., 2003, 'Predictions of employees perceptions of knowledge sharing cultures', Leadership and Organisational Development Journa 24(5), 294-301. http://dx.doi.org/10.1108/01437730310485815

Corso, M., Martini, A., Paolucci, E. \& Pellegrini, L., 2003, 'Knowledge management configurations in Italian small-to-medium enterprises', Integrated Manufacturing Systems 14(1), 46-56. http://dx.doi.org/10.1108/09576060310453344

Davenport, T.H. \& Prusak, L., 1998, Working knowledge: How organisations manage what they know, Harvard Business School Press, Boston, MA.

Davenport, T.H. \& Grover, V., 2001, 'General perspectives on knowledge management: Fostering a research agenda, Guest editor's introduction Special Issue: Knowledge Management', Journal of Management Information Systems 18(1), 3-4.

Davis, R., Watson, P. \& Man, C.L., 2007, 'Knowledge management for the quantity surveying profession, Strategic integration of surveying services', paper presented at the FIG Working Week, Hong Kong SAR, China 13-17 May.

Earl, M., 2001, 'KM strategies: Towards a taxonomy', Journal of Management Information Systems 18(1), 215-233.

Finestone, N. \& Snyman, R., 2005, Corporate South Africa: making multicultural knowledge sharing work. Journal of Knowledge Management 9(3), 128-141. http://dx.doi.org/10.1108/13673270510602827

Franken, A. \& Braganza, A., 2006, 'Organisational forms and knowledge management: One size fits all', International Journal of Knowledge Management Studies 1(1-2), 18-37. http://dx.doi.org/10.1504/IJKMS.2006.008843

Garud, R. \& Kumaraswamy, A., 2005, Vicious and virtuous circles in the Management of knowledge: the case of infosys technologies. Mis quarterly 29(1), 9-33.

Gupta, A.K. \& Govindarajan, V., 2000, 'Knowledge flows within multinational companies', Strategic Management Journal 21(4), 473-496. http://dx.doi. org/10.1002/(SICI)1097-0266(200004)21:4<473::AID-SMJ84>3.0.CO;2-1

Grant, R.M., 1991, 'The resource-based theory of competitive advantage: Implications for strategic formulation', California Management Review, 33(3), 14-135.

Grey, D., 1998, 'Knowledge management and information management: The differences', in Smith Weaver Smith Inc., viewed 26 May 2008, from www. smithweaversmith.com $/ \mathrm{km}$-im.htm

Hasanali, F., 2002, 'The critical success factors of knowledge management', viewed 31 August 2005, from http://www.kmadvantage.com/docs/km 
Jennex, M.E., Smolnik, S. \& Croasdel, D., 2008, 'Towards measuring knowledge management success', in R. Sprague (ed.), Proceedings of the 41st Internationa management Conference on System Science, Waikoloa, Big Island, Hawaii, USA, IEEE Computer Society, 2008.

Kazimi, J., Dasgupta, R.R. \& Natarajan, G., 2004, 'The rise, fall and rise of knowledge management', viewed 12 August 2007, from http://www.zenzar.com/pdfs/km2.pdf

Kim, J.A., 2006, 'Measuring the impact of knowledge management', IFLA Journal 32(4), 362-367. http://dx.doi.org/10.1177/0340035206074075

King, N., Kruger, C.J. \& Pretorius, J., 2007, 'Knowledge management in a multicultura environment: A South African perspective', Aslib Proceedings 59(3), 285-299. http://dx.doi.org/10.1108/00012530710752061

Kruger, C.J. \& Snyman, M.M.M., 2007, 'A guideline for assessing the knowledge management maturity of organisations', South African Journal of Information Management 9(3), viewed 15 October 2007, from http://www.sajim.co.za/index php/SAJIM/article/view/34. http://dx.doi.org/10.4102/sajim.v9i3.34

Kruger C.J. \& Johnson, R.D., 2010, 'Information Management as an enabler of knowledge management maturity: A South African perspective', Internationa Journal of Information Management 30(1), 57-67. http://dx.doi.org/10.1016/j. ijinfomgt.2009.06.007

Kruger, C.J. \& Johnson, R.D., 2011, 'Is there a correlation between knowledge management maturity and organisational performance?', VINE - The Journal of Information and Knowledge Management Systems 41(3), 265-295.

Lee, K.C., Lee, S. \& Kang, I.W., 2005, 'KMPI: Measuring KM performance', Information and Management 42(1), 469-482.

Martiny, M., 1998, 'Knowledge management at HP consulting', Organisational Dynamics, August, pp. 71-78. http://dx.doi.org/10.1016/S0090-2616(98)90025-0

Mabey, C., Salaman, G.J. \& Storey, J., 2001, 'Organisational structuring and restructuring', in G. Salaman (ed.), Understanding Business Organisations, Routledge, London.

McGovern, G. \& Norton, R., 2002, 'Content critical: Gaining competitive advantage through high-quality web content', Pearson Education, London.

McMillan, E., 2002, 'Considering organisation structure and design from a complexity paradigm perspective' in G. Frizzelle \& H. Richards (eds.), Tackling industrial complexity: the ideas that make a difference, pp. 123-136, Institute of Manufacturing, University of Cambridge.

Moffet, S. \& McAdam, R., 2006, 'The effects of organisational size on knowledge management implementation: opportunities for small firms?', Total Quality Management and Business Excellence 17(2), 221-241. http://dx.doi.org/10.1080/ 14783360500450780

Nasir, J., 2003, Impact of globalisation and knowledge management within a high tech manufacturing environment, IBM Software Lab, Dublin.

Nor, F.M. \& Egbu, C., 2010, 'The impact of organisation size on the implementation of knowledge sharing practice in quantity surveying firms in Malaysia', Papers and postgraduate papers from the special track held at the CIB World Building Congress 2010, 10-13 May 2010, pp. 234-244, The Lowry, Salford Quays, United Kingdom, viewed 12 June 2011, from http://cibworld.xs4all.nl/dl/publications/ w102_pub349.pdf
Prime, N., 1999, 'Cross-cultural management in South Africa: Problems, obstacles, and solutions in companies', viewed 07 June 2011, from www.marketing.byu.edu/

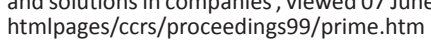

Profile's Stock Exchange Handbook, July-December, 2005, Profile Media, Pietermaritzburg, Kwa-Zulu Natal.

Ryu, C., Kim, Y.J., Chaudhury, A. \& Roa, H.R., 2005, 'Knowledge acquisition via three learning processes in enterprise enformation portals: Learning-by-investment, Learning by-doing, and Learning-from-others', MIS Quarterly 29(2), 245-278.

Sadler-Smith, E., Sargeant, A. \& Dawson, A., 1998, 'Higher level training and SME's', International Small business Studies 30(2), 84-94.

Sanghani, P., 2008, 'Does organisation size matter for starting a knowledge management program?', The Icfai University Journal of Knowledge Management 6(1), 7-20.

Salojarvi, S., Furu, P. \& Sveiby, K., 2005, 'Knowledge management and growth in Finnish SMEs, Journal of Knowledge Management 9(2), 103-122. http://dx.doi. org/10.1108/13673270510590254

Serenko, A., Bontis, N. \& Hardie, T., 2007, 'Organisational size and knowledge flow: A proposed rheoretical link', Journal of Intellectual Capital 8(4), 610-627. http:// dx.doi.org/10.1108/14691930710830783

Snyman, M.M.M. \& Kruger, C.J., 2004, 'The interdependency between strategic management and strategic knowledge management', Journal of Knowledge Management 8(1), 5-19. http://dx.doi.org/10.1108/13673270410523871

Štrach, P. \& Everett, A.M., 2006, 'Knowledge transfer within Japanese multinationals: Building a theory', Journal of Knowledge Management 10(1), 55-68. http:// dx.doi.org/10.1108/13673270610650102

Stoel, L., 2002, 'Retail cooperatives: Group size, Group identification, communication frequency and relationship effectiveness', International Journal of Retail and Distribution Management 30(1), 51-60. http://dx.doi.org/10.1108/ 09590550210415257

Wilson, T.D., 2002, 'The nonsense of knowledge management', Information Research, $8(1), 144$

Xu, J. \& Quaddus, M., 2007 'Exploring the factors influencing end users' acceptance of knowledge management systems: Development of a research model of adoption and continued use', Journal of Organisational and End User Computing 19(4), 54-79. http://dx.doi.org/10.4018/joeuc.2007100104

Xu, J., Quaddus, M., Sankaran, S. \& Faranda, B., 2005, 'Does size matter in knowledge management: A comparison between large Organisations and SMEs', in Proceedings of the Fifth International Conference on Electronic Business, Hong Proceedings of the Fifth International

Zack, M.H., 1999, 'Developing a knowledge strategy', California Management Review 41(3), 125-145. http://dx.doi.org/10.2307/41166000

Zaim, H., Tatoglu, E. \& Zaim, S., 2007, 'Performance of knowledge management practice: A causal analysis', Journal of Knowledge Management 11(6), 54-67. http://dx.doi.org/10.1108/13673270710832163

Zanjani, M.S., Mehrasa, S. \& Modiri, M., 2009, 'Organisational dimensions as determent factors of KM approaches in SMEs', International Journal of Human Science 4(8), 590-595. 